\title{
Computed axial tomography evidence of left atrial enlargement: a predictor of elevated pulmonary capillary wedge pressure in pulmonary hypertension
}

This article was published in the following Dove Press journal:

International Journal of General Medicine

21 December 2009

Number of times this article has been viewed

Z Safdar

MF Katz

AE Frost

Division of Pulmonary-Critical Care Medicine, Baylor College of Medicine, Houston, Texas, USA
Correspondence: Z Safdar Division of Pulmonary-Critical Care Medicine, Baylor College of Medicine, 6620 Main Street, Suite I IB.09, Houston, Texas, 77030, USA Email safdar@bcm.tmc.edu
Background: One of the commonest causes of pulmonary hypertension (PH) is left heart dysfunction associated with elevated pulmonary capillary wedge pressure (PCWP). In contrast, the pathology of pulmonary arterial hypertension (PAH) originates in the pulmonary vascular bed. Accurate diagnosis of PAH requires right heart catheterization (RHC) with normal PCWP. This study examines the role of computed tomography of the chest (CT chest) in evaluating left atrial (LA) size as an indicator of elevated PCWP in patients undergoing PH evaluation.

Methods: CT chest and RHC data were reviewed in 37 subjects at the Baylor PH Center. Both subjective estimates and objective measurements of left atrial size from the CT chest were recorded separately by 3 investigators. Patients were categorized as Group I (small-normal LA) and Group II (large LA) and RHC results compared. The objective and subjective measurements were compared by receiver operator characteristic (ROC).

Results: The mean PCWP was $12 \pm 6 \mathrm{mmHg}$ in Group I and $21 \pm 7 \mathrm{mmHg}$ in Group II $(P=0.001)$. The estimated LA area was $19.4 \pm 4.9 \mathrm{~cm}^{2}$ in Group I and $39.9 \pm 7.6 \mathrm{~cm}^{2}$ in Group II (mean $\pm \mathrm{SD} ; P<0.001$ ). The estimated LA area, corrected for the chest wall length, was $0.78 \pm 0.19 \mathrm{~cm}^{2}$ and $1.65 \pm 0.26 \mathrm{~cm}^{2}$ in Groups I and II, respectively $(P<0.001)$. Significant correlations were found between uncorrected PCWP and LA area $(\mathrm{R}=0.45, P=0.005)$, corrected PCWP and LA area $(\mathrm{R}=0.47, P=0.003)$, and the subjective observer impression of LA enlargement and measured PCWP $(\mathrm{R}=0.51, P=0.001)$.

Conclusion: In this pilot study, enlarged LA area on the CT chest was associated with an elevated PCWP on RHC. For patients undergoing PH evaluation, increased LA area on CT chest could suggest left heart dysfunction in patients as a possible cause of $\mathrm{PH}$.

Keywords: pulmonary capillary wedge pressure, diastolic dysfunction, right heart catheterization, radiology, left atrial area

\section{Introduction}

Pulmonary arterial hypertension (PAH) is a devastating disease with $50 \%$ mortality at 2.8 years in patients left untreated or unresponsive to treatment. ${ }^{1}$ Diagnostic evaluation in patients with pulmonary hypertension ( $\mathrm{PH}$ ) includes an echocardiogram, which when performed as it routinely undertaken even in tertiary referral centers, will diagnose an elevated pulmonary artery pressure. Patients are frequently misdiagnosed as having PAH (diagnostic group I classification [ie, PAH]) and started on PAH-specific therapy based on an echocardiogram in the absence of a right heart catheterization (RHC). When the diagnostic cardiac catheterization is subsequently undertaken, many patients referred for evaluation and treatment of PAH have an elevated pulmonary capillary wedge pressure (PCWP), suggesting left heart 
dysfunction (LHD) (diagnostic group II classification) as a cause of $\mathrm{PH}^{2,3}$ The distinction is important as the prognosis and therapy are different between these two disorders. ${ }^{4}$

The diagnosis of PAH requires a normal PCWP, or a normal left ventricular end-diastolic pressure at the time of cardiac catheterization. ${ }^{5}$ Elevated PCWP may be an indicator of LHD in patients with preserved ejection fraction. LHD is considered a frequent cause of $\mathrm{PH}^{2,6}$ Left atrial (LA) size is considered a marker of LHD with preserved ejection fraction. ${ }^{7-10}$ We undertook this study to examine the role of computed tomography of the chest (CT chest) in evaluating LA size as an indicator of PCWP in patients undergoing $\mathrm{PH}$ evaluation. Our hypothesis was that a LA appearing large on the CT chest would be an indicator of elevated PCWP during a RHC in patients with normal ejection fraction (EF) $(>40 \%)$ and normal aortic and mitral valves.

\section{Methods}

After obtaining institutional review board approval, a retrospective study was undertaken of those patients evaluated for $\mathrm{PAH}$ and underwent a right heart catheterization at Baylor College of Medicine Pulmonary Hypertension Center from July 1, 2005 to June 30, 2006. At this center, CT chest and echocardiography are routine evaluations undertaken for suspected PH. RHC is the gold standard to confirm the diagnosis of pulmonary hypertension. We identified 63 patients who underwent RHC for PH evaluation. Of those patients, 26 were excluded from analysis, 20 due to the absence of a recent (defined as \pm 60 days) CT chest; 3 due to the presence of congenital intra-cardiac shunts which frequently are associated with LA enlargement; 1 due to the presence of lung cancer and significant pleural effusion; and 1 due to failure to obtain PCWP.

CT chests from the remaining 37 patients were reviewed on the Picture Archiving and Communications Systems by 3 independent investigators (adult pulmonologists), 2 of whom were blinded to the name, cardiac catheterization results, and diagnosis of the subjects (MK and AF). Subjective impression of LA size (graded as small-normal or large) was recorded (Figure 1). Approximate LA area was measured as follows: LA area was measured in the mediastinal window at the point where LA appeared largest to the reader (Figure 1); horizontal length (L) and vertical width (W) of the LA were measured; LA area was calculated $(\mathrm{LA}$ area $=\mathrm{L} \times \mathrm{W})$. LA area was corrected for patient size by dividing the calculated area of the LA by the horizontal chest wall length $\left(\mathrm{L}_{\mathrm{cw}}\right)$, measured in the same plane and along the same line as the measurement of the horizontal length of the LA (corrected LA $\left.=[\mathrm{L} \times \mathrm{W}] / \mathrm{L}_{\mathrm{cw}}\right)$ (Figure 1$)$.

The impression of the LA by each investigator was recorded and grouped as either small-normal (Group I) or large (Group II) (Figure 1). When there was agreement between two investigators and disagreement with the third, the impression of the 2 agreeing investigators was accepted. RHC had been undertaken in patients with normal mitral and aortic valves on echocardiogram with preserved left ventricular (LV) systolic function (ie, no evidence of LV systolic failure). Echocardiograms were done at the referral center. No specific instructions were given to the echocardiographers. The provided diagnosis was "PH", therefore, all measurements were the standard evaluations undertaken for a diagnosis of $\mathrm{PH}$.
A

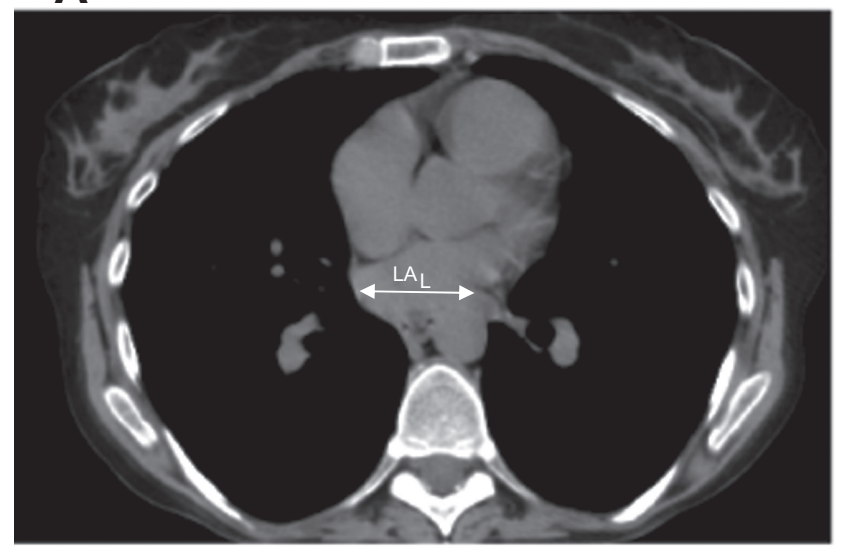

B

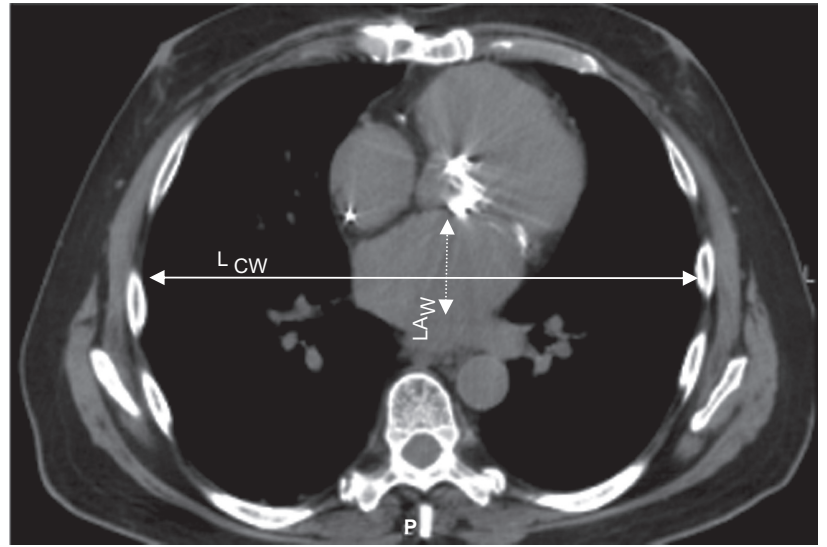

Figure I Computed tomography of chest at the level of left atrium in pulmonary arterial hypertension A) and diastolic dysfunction B) LA size and measurement were determined at the level where the LA appeared largest to the investigator. A) small appearing LA; B) Large appearing LA. Abbreviations: $L A$, left atrium; $L_{C W}$, horizontal chest wall length; $L A_{L}$, horizontal length of $L A ; L A_{W}$ vertical length of $L A$. 


\section{Statistical analysis}

Data are presented as mean \pm SD. Comparisons of all measurements between the two groups were made with unpaired t-test. Values were considered significantly different at $P<0.05$. Pearson correlation analyses of clinical and hemodynamic parameters with LA area and impression of investigators were performed with SPSS software. ShroutFleiss intra-class correlation coefficient was used to measure the inter-rater reliability among the 3 investigators.

\section{Results}

\section{Subjective evaluation of LA size}

There were 29 subjects in Group I and 8 in Group II. The inter-rater reliability calculated using the Shrout-Fleiss intraclass correlation for LA area was 0.865 , indicating acceptable level of agreement among investigators.

The baseline characteristics of these subjects are outlined in Table 1. The estimated LA area was $19.4 \pm 4.9 \mathrm{~cm}^{2}$ in Group I and $39.9 \pm 7.6 \mathrm{~cm}^{2}$ in Group II (mean $\pm \mathrm{SD}$; $P<0.001$ ) (Table 2A). The estimated LA areas corrected for the chest wall length $\left(\mathrm{L} \times \mathrm{W} / \mathrm{L}_{\mathrm{cw}}\right)$ were $0.78 \pm 0.19 \mathrm{~cm}^{2}$ and $1.65 \pm 0.26 \mathrm{~cm}^{2}(P<0.001)$ in Groups I and II, respectively (Table 2B). There was no significant difference in the mean pulmonary artery pressures between the two groups $(P=0.42)($ Table 1$)$

Table I Baseline characteristics of the 37 subjects

\begin{tabular}{|c|c|c|c|}
\hline & Group I & Group II & $P$ value \\
\hline Number of subjects, $\mathrm{N}$ & 29 & 8 & \\
\hline Age, yr & $47 \pm 14$ & $67 \pm 7$ & 0.0009 \\
\hline Females, N (\%) & $24(83)$ & $6(75)$ & 0.019 \\
\hline Race, N & - & - & - \\
\hline Caucasian & 16 & 6 & 0.132 \\
\hline Hispanic & 7 & 0 & 0.352 \\
\hline African-American & 5 & 2 & 0.435 \\
\hline Creatinine, $\mathrm{mg} / \mathrm{dL}$ & $0.98 \pm 0.22$ & $1.0 \pm 0.13$ & 0.81 \\
\hline Body surface area, $\mathrm{m}^{2}$ & $1.98 \pm 0.24$ & $1.94 \pm 0.29$ & 0.73 \\
\hline Body mass index, $\mathrm{kg} / \mathrm{m}^{2}$ & $30 \pm 12$ & $32.5 \pm 11$ & 0.63 \\
\hline Heart rate, beats. $\mathrm{min}^{-1}$ & $85 \pm 13$ & $75 \pm 12$ & 0.056 \\
\hline Mean arterial pressure, $\mathrm{mmHg}$ & $86 \pm 15$ & $85 \pm 9$ & 0.76 \\
\hline $\begin{array}{l}\text { Mean pulmonary artery } \\
\text { pressure, } \mathrm{mmHg}\end{array}$ & $46 \pm 13$ & $42 \pm 13$ & 0.42 \\
\hline Cardiac index, $\mathrm{L} / \mathrm{min} / \mathrm{m}^{2}$ & $2.68 \pm 1.15$ & $3.23 \pm 0.92$ & 0.204 \\
\hline LVEF, \% & $63 \pm 5$ & $56 \pm 9$ & 0.009 \\
\hline $\mathrm{MVO}_{2}, \%$ & $63 \pm 12$ & $66 \pm 13$ & 0.598 \\
\hline
\end{tabular}

Note: Values expressed as mean $\pm S D$.

Abbreviations: LA, left atrium; LVEF, left ventricular ejection fraction; $\mathrm{MVO}_{2}$, mixed venous oxygen consumption.
Correlation of right heart catheterization data and diagnosis with LA size on CT chest

The average time between the RHC and CT chest was $17 \pm 34$ days. The PCWP was $12 \pm 6 \mathrm{mmHg}$ in Group I and $21 \pm 7 \mathrm{mmHg}$ in Group II $(P=0.001)$.

In Group I, 24 subjects had normal PCWP and 5 subjects had elevated PCWP on the RHC. Of the 5 subjects with elevated PCWP, 3 had impaired LV relaxation with preserved LV ejection fraction (LVEF) (range 60\%-70\%), 2 had elevated filling pressures on the echocardiogram suggestive of LHD, and the remaining 2 of the 5 subjects had normal LV filling pressures, LV relaxation, and LA size (Figure 2). In 1 subject with elevated PCWP and a diagnosis of PAH, the RHC revealed marked elevation of both central venous pressure and right ventricular end-diastolic pressure and echocardiogram demonstrated a small LV with cavitary compromise due to markedly abnormal paradoxical interventricular systolic motion secondary to right ventricle systolic pressure overload. The second patient had portopulmonary hypertension and a high cardiac output that may have contributed to the high PCWP.

In Group II, 7 of the 8 subjects had elevated PCWP at time of RHC (Figure 2); 1 subject with normal PCWP also had normal PA pressures during the RHC. This indicates that in all but 1 subject with a large appearing LA on the CT chest, also had elevated PCWP.

Subjective observer impression of LA size correlated with PCWP $(\mathrm{R}=0.51, P=0.001)$. There was a positive correlation between the subjective observer impression of

Table $\mathbf{2} \mathrm{LA}$ area by CT by each investigator, uncorrected $(\mathbf{A})$, and corrected (B)

A.

\begin{tabular}{llll}
\hline Investigator & \multicolumn{2}{l}{ Uncorrected LA area $\left.\mathbf{( c m}^{\mathbf{2}}\right)$} & P value \\
\cline { 2 - 3 } & Group I & Group II & \\
\hline 1 & $19.46 \pm 4.7$ & $41.05 \pm 9.7$ & $<0.002$ \\
2 & $19.19 \pm 5.8$ & $39.05 \pm 3.6$ & $<0.002$ \\
3 & $19.44 \pm 6$ & $39.68 \pm 12$ & $<0.002$ \\
\hline
\end{tabular}

B.

\begin{tabular}{llll}
\hline Investigator & \multicolumn{2}{l}{ Corrected LA area $\mathbf{( c m )}$} & P value \\
\cline { 2 - 3 } & Group I & Group II & \\
\hline 1 & $0.78 \pm 0.12$ & $\mathrm{I} .68 \pm 0.32$ & $<0.002$ \\
2 & $0.77 \pm 0.22$ & $\mathrm{I} .61 \pm 0.14$ & $<0.002$ \\
3 & $0.78 \pm 0.23$ & $\mathrm{I} .63 \pm 0.47$ & $<0.002$ \\
\hline
\end{tabular}

Note: Data values expressed as mean \pm SD.

Abbreviation: LA, left atrium. 


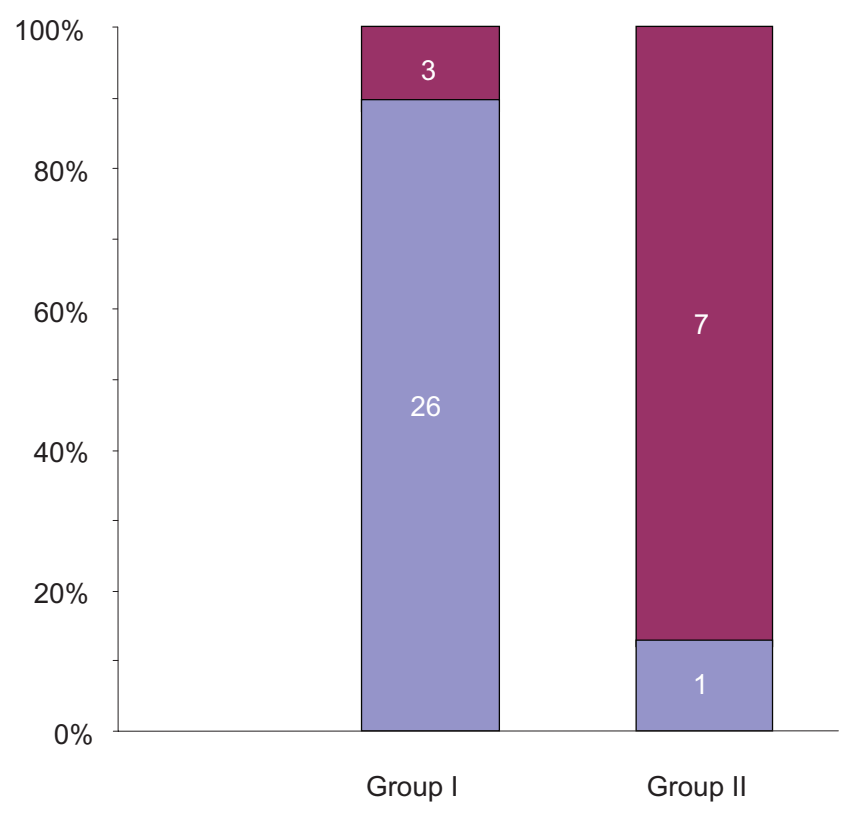

$N=$ 29

8

Left heart dysfunction

No left heart dysfunction

Figure 2 Computed tomography of chest impression of LA in subjects undergoing right heart catheterization for pulmonary hypertension evaluation. Group I, smallnormal appearing LA. Group II large appearing LA. In group I, there were 3 subjects with small-normal appearing LA and elevated PCWP with the evidence of left ventricular dysfunction. Normal PCWP defined as equal to or less than $15 \mathrm{mmHg}$ and elevated PCWP as greater than $15 \mathrm{mmHg}$.

Abbreviations: LA, left atrium; PCWP, pulmonary capillary wedge pressure.
LA size on the CT chest and LA size on measured echocar$\operatorname{diogram}(\mathrm{R}=0.61, P<0.001)$. The positive predictive value (PPV) of the LA size in determining elevated PCWP in PH subjects was $87.5 \%$; negative predictive value (NPV) was $83 \%$. PPV of LA size on CT chest in determining LA size on echocardiogram was $90 \%$; NPV was $67 \%$. These results suggest that looking at the LA on the CT chest may be an indicator of elevated PCWP.

\section{Measurement of LA area and PCWP}

Pearson correlation analysis was conducted to determine whether increased LA area correlated with PCWP. There was a significant correlation between PCWP and estimated LA area, both uncorrected $(\mathrm{R}=0.45, P=0.005)$ and corrected $(\mathrm{R}=0.47, P=0.003$ ) (Figure 3 ). This result indicates that the LA area increases as the PCWP became elevated and may be an important indicator of elevated PCWP. It also suggests that there is no need to correct a LA size measurement for parameters of patient size.

Though no patient had a LVEF $<45 \%$, uncorrected LA area negatively correlated with $\operatorname{LVEF}(\mathrm{R}=-0.34, P=0.03)$ (Table 3) suggesting that as LVEF decreased not unexpectedly LA area increased. This provides some internal consistency and clinical validation of the observation.

To determine if LA area on a CT chest could be used to discriminate between subjects with PAH (diagnostic
A

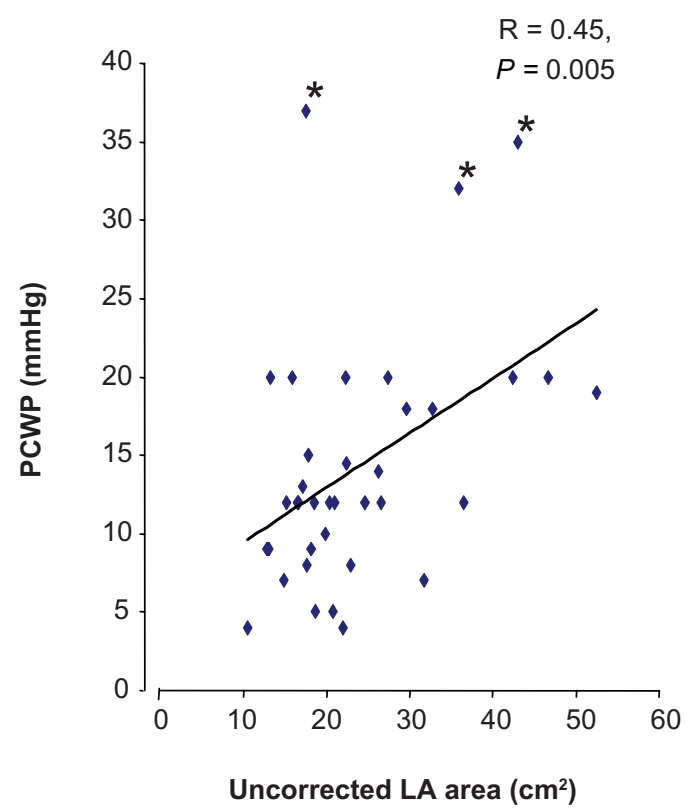

B

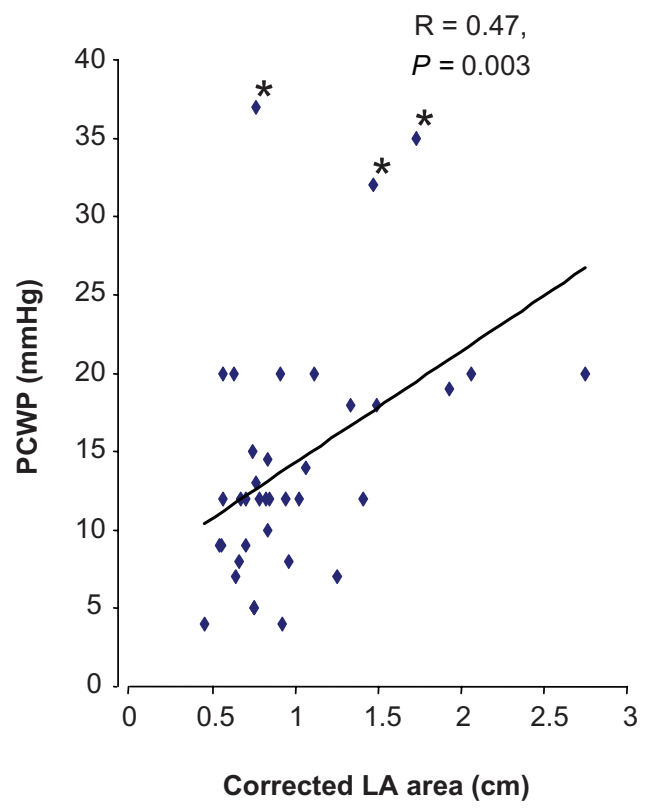

Figure 3 Correlation between PCWP and left atrial area - uncorrected (A) and corrected (B). There were 3 subjects with markedly elevated PCWP ( 37,35 and 32 mmHg) with elevated LA area and had final diagnosis as diastolic dysfunction.

Abbreviations: LA, left atrium; PCWP, pulmonary capillary wedge pressure. 
Table 3 Pearson's correlation analysis of clinical and hemodynamic parameters with LA area (uncorrected and corrected)

\begin{tabular}{llc}
\hline Parameter & R (uncorrected LA area) & R (corrected LA area) \\
\hline Age, years & $-0.08(0.60)$ & $-0.06(0.68)$ \\
Body mass index, $\mathrm{kg} / \mathrm{m}^{2}$ & $-0.178(0.30)$ & $-0.224(0.19)$ \\
Mean arterial pressure, $\mathrm{mmHg}$ & $-0.238(0.15)$ & $-0.211(0.21)$ \\
Mean pulmonary artery pressure, $\mathrm{mmHg}$ & $-0.208(0.2 \mathrm{I})$ & $-0.182(0.28)$ \\
Cardiac output, L/min & $-0.032(0.85)$ & $0.008(0.96)$ \\
Cardiac index, L/min/m² & $-0.011(0.95)$ & $-0.050(0.77)$ \\
LVEF, $\%$ & $-0.345(0.03)^{*}$ & $-0.274(0.10)$ \\
$\mathrm{MVO}_{2}, \%$ & $-0.142(0.40)$ & $-0.133(0.44)$
\end{tabular}

Notes: Pearson correlation (significance); $* P<0.05$.

Abbreviations: LA, left atrium; LVEF, left ventricular ejection fraction; $\mathrm{MVO}_{2}$, mixed venous oxygen consumption.

group I) from those with elevated PCWP (diagnostic group II), we calculated area under the receiver operating characteristic (ROC) curves for both uncorrected and corrected LA area. The largest area under the ROC for uncorrected LA area of $31 \mathrm{~cm}^{2}$ was 0.996 (Figure 4). Therefore, uncorrected LA area of $31 \mathrm{~cm}^{2}$ may be a good diagnostic tool to discriminate between the two groups. Value greater than 1.3 for the corrected LA area yielded a sensitivity and specificity for prediction of left heart failure with preserved EF of $100 \%$. These promising results indicate that both uncorrected and corrected LA area measurements were reasonable values to distinguish between subjects with

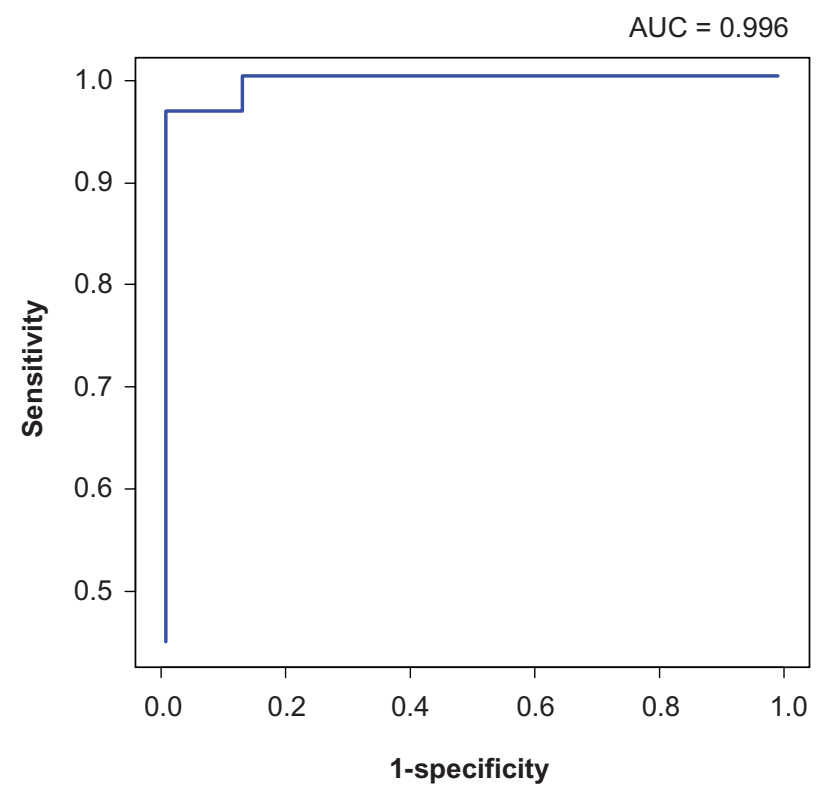

Figure 4 Receiver operating characteristic curve for distinguishing Group I and Group II based on the uncorrected LA area on the computed tomography of the chest. Abbreviations: AUC, area under the receiver operating characteristic curve; LA, left atrium. elevated PCWP (diagnostic group II) and pulmonary arterial hypertension (diagnostic group I).

\section{Discussion}

Clinical suspicion of $\mathrm{PH}$ is usually confirmed by an echocardiogram, ${ }^{11}$ which is typically reliable for discriminating systolic dysfunction, valvular lesions, and congenital defects. CT chest is frequently undertaken as part of the routine evaluation of $\mathrm{PH}$ patients to exclude parenchymal lung disease. Estimation or measurement of LA size by CT chest is simple and remarkably reliable, akin to the routine evaluation of heart size from chest X-ray. This study demonstrates the utility of routinely assessing LA size/area in the evaluation of patients with $\mathrm{PH}$. The data presented here indicate that most patients with a large LA on CT chest, even without formal measurement, had elevated PCWP suggestive of LHD. These findings may allow patients to be stratified for risk of PAH enabling prioritization for right heart catheterization and evaluation of the need for initiation of PH specific therapy. In addition inappropriate use of PAH specific therapy could be avoided. ${ }^{4}$

PAH is an orphan disease with a prevalence of 15 cases per million. ${ }^{12}$ In this single center study we present data from 37 patients who underwent both RHC and CT chest within 1 month of each other. There were 26 patients with PAH in Group I, 7 patients had LHD with preserved ejection fraction in Group II. 1 patient in Group II had normal pulmonary artery pressures and PCWP. Three patients in Group I were diagnosed with LHD with preserved ejection fraction based on the findings of impaired LV relaxation on the echocardiogram in all 3 and elevated filling pressures in 2 of the 3 subjects. One of the patients in Group I with elevated PCWP and small appearing LA on CT chest had markedly enlarged right atrium and right ventricle, and small LV with 
shifting of the interventricular septum towards LV on the echocardiogram. This may reflect ventricular interdependence with elevated right ventricular pressure and volume shifting the interventricular septum to the left leading to obliteration of the LV cavity and LV systolic/diastolic dysfunction. This phenomenon, also known as the "reverse Bernheim effect", is increasingly recognized in $\mathrm{PAH}$ populations. ${ }^{13,14}$ The elevated PCWP in left heart failure with preserved EF, on the other hand, is due to the stiffened LV with decrease compliance and associated with enlargement of the LA. ${ }^{15}$ In such cases, LHD results from noncompliance of the LV, which in the presence of normal LV systolic function, produces elevated left ventricular filling pressures (elevated PCWP or LV enddiastolic pressures), ${ }^{16}$ further aggravated by increases in heart rate in response to effort or stress. LHD with preserved EF is the commonest confounding diagnosis in the evaluation and management of patients with $\mathrm{PH}$ and an increasingly frequent diagnostic entity in the aging, diabetic, and hypertensive population. Evaluation of echographic parameters of LHD is beyond the scope of this paper and will be undertaken in subsequent studies.

LA size is considered a marker of LHD with preserved ejection fraction. ${ }^{7-10}$ Advancing age alone does not contribute to LA enlargement and the impact of gender on LA volume may be due to differences in body surface area. ${ }^{8}$ However, in our study there was no difference in the body surface area or body mass index between the two groups (Table 1). Factors influencing LA size include valvular abnormalities and atrial arrhythmias. ${ }^{17}$ None had atrial fibrillation at the time of RHC. Prevalence of LHD with preserved EF is high and treatment remains poorly defined, risk factors include: essential hypertension, obesity, obstructive sleep apnea, renal failure, thyroid dysfunction, female gender, and older age. ${ }^{16,18,19}$

Patients may be presumptively started on $\mathrm{PAH}$ specific therapy without undergoing a diagnostic RHC. A CT chest, however, can be easily and non-invasively undertaken and our data indicates LA size could give an indication of the presumed diagnosis pending RHC. The impression of LA enlargement on CT in patients undergoing evaluation for PH may be an important predictor that $\mathrm{PH}$ specific therapy was not indicated. This data should not be construed as a recommendation to base diagnosis of $\mathrm{PH}$ on $\mathrm{CT}$ chest without proceeding to $\mathrm{RHC}$ but rather to identify patients at risk of LHD with enlarged LA.

Different imaging techniques such as 2- or 3-dimensional echocardiography, magnetic resonance imaging, and cine computerized tomography, have been used to estimate LA size and/or volume. ${ }^{20-23}$ These techniques are limited by availability, technical difficulties, time requirements, or need for special software. ${ }^{20,24}$ Though tertiary care centers have the ability to undertake an echocardiography evaluation of patients with suspected $\mathrm{PH}$, such studies have not been validated in large trials nor are they routinely applied to all echocardiograms evaluations. ${ }^{25-27}$ Our data demonstrate that a routine $\mathrm{CT}$ chest may be used to reliably predict elevated PCWP that may suggest the diagnosis of LHD in patients with preserved LV systolic function and echocardiograhic evidence of $\mathrm{PH}$.

\section{Conclusion}

Estimation of LA size by CT chest may avoid initiation of unnecessary and inappropriate $\mathrm{PH}$-specific therapy and delays in diagnostic $\mathrm{RHC}$ in patients undergoing $\mathrm{PH}$ evaluation.

\section{Limitations of the study}

The limitations of this study were the retrospective study design, small sample size, and one center review. LA area and impression may have been influenced by the cardiac cycle at the time of the CT chest and intravascular volume status of the patient. However, these determinations are beyond the scope of this study. Furthermore, future studies that prospectively and simultaneously evaluate the echocardiographic and hemodynamic parameters in patients undergoing $\mathrm{PH}$ evaluation will be needed. The results of this single-center study will need to be validated in a large prospective multicenter study.

\section{Acknowledgment}

The authors would like to thank Mr Degang Wang for help with the manuscript.

\section{Disclosures}

None of the authors have a financial relationship with a commercial entity that has an interest in the subject of this manuscript.

\section{References}

1. Humbert M, Sitbon O, Chaouat A, et al. Pulmonary arterial hypertension in France: results from a National Registry. Am J Respir Crit Care Med. 2006;173:1023-1030.

2. Oudiz RJ. Pulmonary hypertension associated with left-sided heart disease. Clin Chest Med. 2007;28:233-241.

3. Simonneau G, Galie N, Rubin LJ, et al. Clinical classification of pulmonary hypertension. J Am Coll Cardiol. 2004;43:5S-12S.

4. Califf RM, Adams KF, McKenna WJ, et al. A randomized controlled trial of epoprostenol therapy for severe congestive heart failure: The Flolan International Randomized Survival Trial (FIRST). Am Heart J. 1997;134:44-54. 
5. Rubin LJ. Diagnosis and management of pulmonary arterial hypertension: ACCP evidence-based clinical practice guidelines. Chest. 2004; $126: 4 S-6$ S

6. Simonneau G, Robbins IM, Beghetti M, et al. Updated clinical classification of pulmonary hypertension. J Am Coll Cardiol. 2009; 54:S43-S54

7. Rossi A, Vassanelli C. Left atrium: no longer neglected. Ital Heart J. 2005;6:881-885

8. Pritchett AM, Jacobsen SJ, Mahoney DW, et al. Left atrial volume as an index of left atrial size: a population-based study. J Am Coll Cardiol. 2003;41:1036-1043

9. Gottdiener JS, Kitzman DW, Aurigemma GP, et al. Left atrial volume, geometry, and function in systolic and diastolic heart failure of persons $>$ or $=65$ years of age (the cardiovascular health study). Am J Cardiol. 2006;97:83-89.

10. Rossi A, Cicoira M, Florea VG, et al. Chronic heart failure with preserved left ventricular ejection fraction: diagnostic and prognostic value of left atrial size. Int J Cardiol. 2006;110:386-392.

11. McGoon M, Gutterman D, Steen V, et al. Screening, early detection, and diagnosis of pulmonary arterial hypertension: ACCP evidence-based clinical practice guidelines. Chest. 2004;126:14S-34S.

12. Humbert M, Sitbon O, Chaouat A, et al. Pulmonary arterial hypertension in france: results from a national registry. Am J Respir Crit Care Med. 2006;173:1023-1030.

13. Santamore WP, Dell'Italia LJ. Ventricular interdependence: significan left ventricular contributions to right ventricular systolic function. Prog Cardiovasc Dis. 1998;40:289-308.

14. Shapiro BP, McGoon MD, Redfield MM. Unexplained pulmonary hypertension in elderly patients. Chest. 2007;131:94-100.

15. How to diagnose diastolic heart failure. European Study Group on Diastolic Heart Failure. Eur Heart J. 1998;19:990-1003.

16. Angeja BG, Grossman W. Evaluation and management of diastolic heart failure. Circulation. 2003;107:659-663.

17. Kernis SJ, Nkomo VT, Messika-Zeitoun D, et al. Atrial fibrillation after surgical correction of mitral regurgitation in sinus rhythm: incidence, outcome, and determinants. Circulation. 2004;110:2320-2325.
18. Alpert MA, Hashimi MW. Obesity and the heart. Am J Med Sci. 1993;306:117-123.

19. Mathew ST, Gottdiener JS, Kitzman D, et al. Congestive heart failure in the elderly: the Cardiovascular Health Study. Am J Geriatr Cardiol. 2004;13:61-68.

20. Khankirawatana B, Khankirawatana S, Lof J, et al. Left atrial volume determination by three-dimensional echocardiography reconstruction: validation and application of a simplified technique. J Am Soc Echocardiogr. 2002;15:1051-1056.

21. Lester SJ, Ryan EW, Schiller NB, et al. Best method in clinical practice and in research studies to determine left atrial size. Am J Cardiol. 1999;84:829-832.

22. Schwartzman D, Lacomis J, Wigginton WG. Characterization of left atrium and distal pulmonary vein morphology using multidimensional computed tomography. J Am Coll Cardiol. 2003;41:1349-1357.

23. Tsang TS, Barnes ME, Gersh BJ, et al. Left atrial volume as a morphophysiologic expression of left ventricular diastolic dysfunction and relation to cardiovascular risk burden. Am J Cardiol. 2002;90: 1284-1289.

24. Apfel HD, Shen Z, Gopal AS, et al. Quantitative three dimensional echocardiography in patients with pulmonary hypertension and compressed left ventricles: comparison with cross sectional echocardiography and magnetic resonance imaging. Heart. 1996;76: 350-354.

25. Celermajer DS, Marwick T. Echocardiographic and right heart catheterization techniques in patients with pulmonary arterial hypertension. Int J Cardiol. 2008;125:294-303.

26. Selimovic N, Rundqvist B, Bergh CH, et al. Assessment of pulmonary vascular resistance by Doppler echocardiography in patients with pulmonary arterial hypertension. J Heart Lung Transplant. 2007;26: 927-934.

27. Lanzarini L, Fontana A, Campana C, et al. Two simple echo-Doppler measurements can accurately identify pulmonary hypertension in the large majority of patients with chronic heart failure. J Heart Lung Transplant. 2005;24:745-754.
International Journal of General Medicine

\section{Publish your work in this journal}

The International Journal of General Medicine is an international, peer-reviewed open-access journal that focuses on general and internal medicine, pathogenesis, epidemiology, diagnosis, monitoring and treatment protocols. The journal is characterized by the rapid reporting of reviews, original research and clinical studies across all disease areas.

\section{Dovepress}

A key focus is the elucidation of disease processes and management protocols resulting in improved outcomes for the patient.The manuscript management system is completely online and includes a very quick and fair peer-review system. Visit http://www.dovepress.com/ testimonials.php to read real quotes from published authors. 